\title{
Letter from America
}

\section{Reconsidering quality}

\author{
J Kisslo
}

\section{To my friend in echocardiography}

Greetings from the $32^{\text {nd }}$ best country in international soccer (that's football to you).

News of our demise in the Coupe du Monde made the fifth page of the sports section in my hometown newspaper. This failure raised a low grade murmur about the quality of our soccer that will surely continue well into the millenium and extend somewhat beyond our players and ex-coach. President Clinton explained it away saying, "Soccer came late to Americans ..." Thank you, Bill.

I understand the rules of modern soccer were codified by some Englishmen, probably disgruntled by cricket, in the mid- $19^{\text {th }}$ century. The score of the first international game (1871) between England and Scotland was a rousing $0-0$. From there all the hoopla spread around the world, skipping North America. The cup web site calls the game the "common destiny of mankind".

You say we are a violent culture, but we watched as those young men were tripped by each other (or invisible feet) and fell to the ground in extraordinary pain. Oh the agony we felt, watching those unfortunate players carried off the field by stretcher. We felt relief when they arose miraculously from some unseen cure and came right back into the game. I concluded that most players must compete for Lourdes during the regular season.

How can the US be so far apart from the rest of the world in quality of this game? What is quality anyway? Ah, you say the fans love it and that is plenty reason enough.

I'm just a poor physician thinking about quality in my little world. We've talked about it before. $^{2}$ I can think of three reasons why we physicians worry about quality. The first, and probably the most agreeable, is that we have concern for our patients. Yes, even a first year medical student will tell you that this is surely the overwhelming reason we are all captivated by quality issues in medicine.

Since this letter will never be read by non-physicians, we are safe to admit that there some of us who take this argument a bit too far. Generically, "patients will die" unless we get what we want from administrators or bureaucrats is the extreme form of this invocation. While I have never, ever, met any of these unsavoury physicians, I am told that there are some among us who commonly use this argument.
The second is that we take pride in our noble profession. No, no, I don't mean the sinful self pride kind of thing. I'm talking about noble self pride that recognises that we serve humanity and science and that our goals should be pure. Maybe it is a bit like medieval knighthood. "My son is a doctor," said my mother. Yes, I wore my white coat, bravery, stethoscope, sleeplessness, blue blazer, grey slacks and an appropriate dose of ego to match. Surely her friends assumed I had dignity, bearing, and the very disposition they expected.

The third reason to consider quality is simply as a response to protect our profession by providing evidence of worth or merit. Given the first two reasons, it is hard to believe that any protection is necessary. In addition, echo use is booming worldwide. You're part of it (as only echo addicts will read this letter) and what could possibly be a threat? Educational meetings are growing in number and size as society treasuries grow. There are more and more really improved echo machines over the last two years, unlike the lightweight fluffy marketing products of the previous decade.

Over the past year we patted each other on the back, slapped some high fives and showed some more very colourful slides of diseases and diagrams - my favourite is now bubbles resonating, then imploding. All graphs and charts showed things going mostly somewhere upwards. Yep, the bubbles are resonating, $3 \mathrm{D}$ is looking in directions we never saw before, and all is being carried on $1 \mathrm{~s}$ and 0 s over the echo horizon into the next millennium. Now, in this milieu, it's hard to believe that echo can be threatened in any way.

Maybe we are just part of the exaggerated tendency to set standards and definitions in all fields. How about the recent European Community regulations concerning how much curve should be tolerated in a cucumber before the EC calls it a cucumber and allows it to be sold? Forget nutrition and starving people, the purpose of a cucumber is to be straight and straight it will be in the EC.

The EC obviously followed the American echo community in trying to do right for the world. We set forth very good standards for echo over the years. ${ }^{2}$ You know what I mean, we want physicians to train for so many months/ years, and to do so many cases, and even to take a test to show their high quality. We even have some new groups you should know about. The National Board of Echocardiography (the suc-
Professor Kisslo.

email: joseph.kisslo@duke edu 
cessor to the ASEeXam) will test you and ICAEL (Intersociety Commission for Accreditation in Echocardiography) will accredit your lab. I see that you are doing the same in your countries around the world. We were all pleased here when our Brazilian Fellow passed his country's exam.

So, that's the trilogy right now: concern, pride and protection. And it's clearly evident that this modern culture of echo belief (probably medicine too) has two measures of quality: numbers and tests. Read the recommendations of any society and see. ${ }^{2}$ The American College of Cardiology and the American Society of Echocardiography are famous for this. Look at the work of the Dutch Academy of Science this spring/summer as they reviewed cardiology programmes. Rumour has it they were even double checking the existence of publications (on the internet) just in case some programme director exaggerated a claim or two. Number of articles and number of degrees are the important things in this modern world of quality.

I'll accept that some numbers and some tests are necessary. In some cases they represent basic competence. The Spice Girls are now down to four at this time of writing. Ginger is gone, the girl power movement is threatened, and the number logic maintains that five Spices work and four do not. By this time you have figured out that numbers and tests can be distorted measures of quality.

Sorry, the numbers arguments equating to quality just don't make it for me and never will. What profession uses numbers better than astrophysics? Remember about a year ago when the Harvard-Smithsonian Center for Astrophysics was notified by a young astronomer from the University of Arizona that asteroid 1997 XF11 was going to come precariously close to the earth (30 000 miles) on 26 October 2028. The International Astronomical Union immediately published news of this killer asteroid. Now I figured these guys are better at time and distance than any of us could ever be on measuring left ventricular volume.

Thirty thousand lousy miles is about what some of us put on our frequent flyer programmes in a month, so I got scared! This Doomsday scenario included a potential collision with the earth resulting in $80-90 \%$ of the world's echo machines being pulverised. Any calculations predicting the end of mankind are clearly more important than any of us echo people measuring the ratio of $\mathrm{A}$ and $\mathrm{E}$ waves.

Table 1 Deming's 14 quality points. ${ }^{8}$ Adapted for echocardiography

1. Constantly improve echo services

2. Adopt the new philosophy

3. Cease dependence on inspection (or tests) to achieve quality

4. End buying echo machines on the basis of price (high or low). Worry about service delivery instead

5. Improve, constantly and forever, every process for planning, learning, and implementing echo services

6. Instill training on the job

7. Adopt and instill leadership

8. Drive out fear and blame

9. Break down barriers between staff and have everybody work together

10. Eliminate slogans, exhortations as targets for the work force

11. Eliminate numerical quotas for employees and numerical goals for management

12. Remove barriers that rob people of pride, such as annual ratings or merit system

13. Institute a vigorous programme of education and self improvement for everyone

14. Put everybody related to echo lab to work to accomplish the transformation
Ah, but we were saved by the good folks at Jet Propulsion Laboratory who said the near miss was miscalculated by 600000 miles. Not to worry, NASA then announced that it would sponsor the business of quality asteroid watching/measuring/calculating using an international committee of astronomers whose business it would be to officially announce Doomsday. Mind you, NASA has an entire budget of $\$ 1.8$ million/year set aside for asteroid watching. At current charges in the US, this might bring you about 2000 echo/Doppler studies.

OK, there are some problems. We echo people spend a lot of money $(20 \%$ of all cardiology in the US). Look at the good we do. We want to keep this good thing going and our training and practice standards are just the thing to do that. No perfidy here.

Quality, like love, is hard to define. We know it when we see it. There's no data anywhere that the concern, pride or protective approaches of the last several decades have made any bit of difference about anything. Maybe nobody has looked, but I think we've got it all wrong. Nobody, except us, is paying any attention. And we sure aren't making a big impression on the people who pay the bills in any country. Our US payments are going down $52 \%$ for a chest wall echo over the next four years (after $50 \%$ in the last four years). Machine sales are slumping.

Maybe it is all just echo babble. It's like me trying to convince the traffic police at my hospital that I am deserving of a select parking place because I am a licensed physician, I am trained in echo, I save lives and I am in hurry. I still get ticketed.

In case you missed my point, our definitions of quality stink. Maybe we should look for something new.

Quality assessment seems to be a very well defined component of business practice. Bergman and Klefso ${ }^{3}$ said, "the quality of a ... product or service is its ability to satisfy the needs and expectations of the customers". This definition is remarkably like the International Standard IAO8402 Quality Vocabulary (and in the IAO 900 series) that states, "Quality is the totality of features and characteristics of a product or service that bear on its ability to satisfy stated or implied needs." ${ }^{4}$ How far off can we be?

Sure, I agree that the American Society of Echocardiography quality document was a pretty good attempt to explain the whole thing. ${ }^{5}$ But it seems like no one is reading. For sure, we have a lot more to learn.

The modern quality movement started with Walter A Shewhart in a 1924 Bell Labs memorandum. He said (paraphrased), "Human wants are fulfilled through the fabrication of ..... (services) of different kinds and that these wants can be quantified." ${ }^{\prime}$ In the 1940 s, Harold Dodge and Harry Romig developed their statistical modelling to judge quality. ${ }^{7}$ The fact that recipients of a service have the most knowledge about judging desired quality is quite extraordinary, particularly to physicians.

Echo people with distorted notions of quality should remember that medical schools 
on all sides of World War II were cranking out two and three classes of physicians a year. Complaint was that these "quickie" docs were not the quality of what was usual. But they could dispense Alexander Fleming's miracle penicillin (and save lives) just as well as those trained according to traditional long curricula. Now you're starting to understand quality better. It's saving lives and suffering, not test passing.

As the war closed, W Edwards Deming began to write about quality improvement and to bring these developing concepts together in actual practice in Japan's miracle rebuilding economy. Coming off wartime, the US and Europe just wanted to do things the old way and paid little attention. You should know his ideas revolutionised the practices of business and business management. Nowadays, yearly international quality awards named for Deming are the world's most prestigious. Table 1 shows his famous 14 points, adapted for echo. ${ }^{8}$

It seems that we physicians need to get to work about redefining quality in some new way. Medicine appears to be quality deprived in the modern era. Ever wonder why your colour television set works so reliably? Thank Deming. We medical people still assess quality by ancient methods and standards.

The greatest weakness in the current methods of assessment of quality in medicine is that they end when the training requirements are fulfilled or the tests are passed. Hello, doctor. As a patient, I want to know more than the fact that you can keep your glutei in a chair in a darkened room for more than a year practising your echoes and that you could cram for a test.

The first thing is trying to translate, as nearly as possible, the wants of patients into characteristics of echo (medical) services to satisfy these wants. The second thing is to set up ways and means to measure our ability to fill these wants in meaningful ways, rather than our own arbitrary, but well intentioned standards. Wow, are all our numbers and tests wrong, or just a step along the way?

One thing is for sure, it is easy to get confused about quality. I read that millions of shamrocks worn in Ireland on St Patrick's Day were mostly grown from seedlings imported from New Zealand. In case you don't know, those shamrocks are the little green three leafed plants that the Irish provide to the world as symbols of good luck. Supposedly, magical little elves secretly harvest these tiny plants in the misty fields of Ireland.

Does this mean that the Kiwis are now in charge of good luck? Do they check the quality of luck the same way the Irish did? What happened to the elves? People need good luck like they need good health. Quality is just a mess everywhere. If the elves are out of jobs harvesting shamrocks, have they turned to echo and is anybody watching them?

Now you get it, don't you? Nobody ever measured the incidence of good luck with genuine or Kiwi grown shamrocks. What's more, it makes no difference to either of us where our shamrocks come from. Just wear your shamrock next year and drink your beer when the time comes for celebration.

In the meantime, why don't we all start dealing with quality issues in a new way? If you don't, I will. When I get it right, I'm coming over to sell my quality tested echoes at a cheaper price. The world is getting smaller and smaller and our economies are intertwined. But it's better to do it together. Can we try?

By the way, are y'all going to do this football cup thing in another four years?

1 http://www.worldcup.com/english/history/history_of/ football.html. July 1998

2 Kisslo J. A letter from America. Br Heart 7 1995;73(suppl 2):33-6.

3 Bergman B, Klefsio B. Quality from customer needs to customer satisfaction. London: McGraw Hill Book Co, 1994.

4 Gummesson E. Quality-the Ericsson approach. Stockholm: Ericsson, HF/DHQC, 1988.

5 Kisslo J, Byrd BF, Geiser EA, et al. Recommendations for the continuous quality improvement in echocardiography. 7 Am Soc Echocardiogr 1995;8:S1-S28.

6 Shewhart WA. Economic control of quality of manufactured product. New York: Van Nostrand, 1931.

7 Dodge HF, Romig HG. Single sampling and double sampling inspection table. Bell System Technical fournal 1941;20:1-61.

8 Deming WE. Out of the crisis. Cambridge, Massachusetts: Cambridge University Press, 1986. 